\title{
CICLAGEM E BALANÇO DE NUTRIENTES NO SISTEMA SOLO-PLANTA EM UM PLANTIO DE Eucalyptus sp., NO DISTRITO FEDERAL ${ }^{(1)}$
}

\author{
Alcides Gatto $^{(2)}$, Angela Pereira Bussinguer ${ }^{(5)}$, Fabiana Campos Ribeiro ${ }^{(5)}$, Gileno Brito \\ de Azevedo ${ }^{(5)}$, Maria Cristina Bueno ${ }^{(4)}$, Marina Morais Monteiro ${ }^{(3)}$ \& Pierre Farias de \\ Souza ${ }^{(5)}$
}

RESUMO

As espécies do gênero Eucalyptus são as mais plantadas no mundo, tornandose solução para diminuir a pressão sobre as florestas nativas. Este trabalho objetivou avaliar a biomassa seca e sua distribuição nos diferentes compartimentos das árvores (folhas, galhos, casca, lenho e raízes), bem como examinar o conteúdo de macronutrientes dela e o balanço de nutrientes no sistema solo-planta, em um plantio de Eucalyptus urophylla $\times$ E. grandis, aos 60 meses de idade, na Fazenda Água Limpa, no Distrito Federal. Os dados foram obtidos de três árvores de eucalipto, que foram cubadas rigorosamente e tiveram as raízes escavadas até a profundidade de $60 \mathrm{~cm}$. Esses dados foram submetidos à análise estatística pela correlação de Pearson. Grande parte da biomassa seca das árvores foi verificada no compartimento lenho $(69,19 \%)$, seguido de raízes $(10,15 \%)$, galhos $(9,75 \%)$, casca $(6,06 \%)$ e folhas $(4,85 \%)$. Os maiores teores de macronutrientes foram detectados nas folhas $\left(\mathrm{N}=13,55 \mathrm{~g} \mathrm{~kg}^{-1} ; \mathrm{P}=1,33 \mathrm{~g} \mathrm{~kg}^{-1} ; \mathrm{K}=8,52 \mathrm{~g} \mathrm{~kg}^{-1} ; \mathrm{Ca}=7,12 \mathrm{~g} \mathrm{~kg}^{-1} ; \mathrm{Mg}=2,44\right.$ $\mathrm{g} \mathrm{kg}^{-1}$; e $\left.\mathrm{S}=1,76 \mathrm{~g} \mathrm{~kg}^{-1}\right)$, enquanto o lenho apresentou os menores $\left(\mathrm{N}=1,73 \mathrm{~g} \mathrm{~kg}^{-1}\right.$; $\left.\mathrm{P}=0,23 \mathrm{~g} \mathrm{~kg}^{-1} ; \mathrm{K}=0,34 \mathrm{~g} \mathrm{~kg}^{-1} ; \mathrm{Ca}=0,20 \mathrm{~g} \mathrm{~kg}^{-1} ; \mathrm{Mg}=0,03 \mathrm{~g} \mathrm{~kg}^{-1} ; \mathrm{e} \mathrm{S}=0,43 \mathrm{~g} \mathrm{~kg}^{-1}\right)$. A ordem dos conteúdos totais de macronutrientes verificada para a parte aérea foi: $N>K$ $>\mathrm{Ca}>\mathrm{S}>\mathrm{Mg}>\mathrm{P}$, enquanto para as raízes, $\mathrm{N}>\mathrm{Ca}>\mathrm{K}>\mathrm{Mg}>\mathrm{S}>\mathrm{P}$. As raízes são responsáveis por acumular aproximadamente $11,90 \%$ dos nutrientes contidos na biomassa das árvores; essa quantidade diminui com o aumento da profundidade. $O$ balanço de nutrientes indica que $\mathrm{P}$ e $\mathrm{S}$ não são suficientes para um novo ciclo da floresta.

Termos de indexação: biomassa, nutrição florestal, sustentabilidade.

(1) Recebido para publicação em 25 de junho de 2013 e aprovado em 26 de março de 2014.

(2) Professor, Departamento de Engenharia Florestal, Universidade de Brasília - UnB. Campus Universitário Darcy Ribeiro. Caixa Postal 4357. CEP 70904-970 Brasília (DF). E-mail: alcidesgatto@unb.br

(3) Mestranda em Ciências Florestais, UnB. E-mail: marinammonteiro@gmail.com

(4) Professora, Departamento de Engenharia Florestal, Universidade Federal do Tocantins - UFT. E-mail: mariabueno@unb.br

(5) Doutorandos em Ciências Florestais, UnB. E-mail: angelabussinguer@gmail.com, fbn.ribeiro@gmail.com, gilenoba@hotmail.com, pierreflorestal@yahoo.com.br 


\title{
SUMMARY: NUTRIENT CYCLING AND BALANCE INTHE Eucalyptus sp. SOIL- PLANT SYSTEM IN THE DISTRITO FEDERAL, BRAZIL
}

\begin{abstract}
The species of the Eucalyptus genus are the most cultivated in the world and have become a solution for reducing the pressure on native forests. The aim of this study was to evaluate the dry biomass and its distribution in the different compartments of the trees (leaves, branches, bark, wood and roots), and assess their macronutrient content and nutrient balance in the soil-plant system in a Eucalyptus urophylla $x$ E. grandis plantation at 60 months of age on the Água Limpa Farm in the Distrito Federal, Brazil. Data were obtained from three eucalyptus trees that had been rigorously scaled and the roots dug to a depth of $60 \mathrm{~cm}$. Data were statistically analyzed by Pearson correlation. Most of the dry weight of the trees was observed in the wood compartment $(69.19 \%)$, followed by roots $(10.15 \%)$, branches $(9.75 \%)$, bark $(6.06 \%)$ and leaves $(4.85 \%)$. The highest levels of macronutrients were observed in leaves $\left(N=13.55 \mathrm{~g} \mathrm{~kg}^{-1}, P=1.33 \mathrm{~g} \mathrm{~kg}^{-1}, K=8.52 \mathrm{~g} \mathrm{~kg}^{-1}, C a=7.12 \mathrm{~g} \mathrm{~kg}^{-1}\right.$, $M g=2.44 \mathrm{~g} \mathrm{~kg}^{-1}$, and $\left.S=1.76 \mathrm{~g} \mathrm{~kg}^{-1}\right)$, while the wood had the lowest concentrations $(\mathrm{N}=1.73$ $\mathrm{g} \mathrm{kg}^{-1}, P=0.23 \mathrm{~g} \mathrm{~kg}^{-1}, K=0.34 \mathrm{~g} \mathrm{~kg}^{-1}, \mathrm{Ca}=0.20 \mathrm{~g} \mathrm{~kg}^{-1}, \mathrm{Mg}=0.03 \mathrm{~g} \mathrm{~kg}^{-1}$, and $\left.\mathrm{S}=0.43 \mathrm{~g} \mathrm{~kg}^{-1}\right)$. The order of total contents of macronutrients observed for tree shoots was $N>K>C a>S>M g>P$ while for the roots it was $N>C a>K>M g>S>P$. The roots accumulate approximately $11.90 \%$ of the nutrients in the biomass of trees, and this amount decreases with increasing depth. The nutrient balance indicates that $P$ and $S$ are not enough for a new growth cycle in the forest.
\end{abstract}

Index terms: biomass, forest nutrition, sustainability.

\section{INTRODUÇÃO}

No Brasil, a grande demanda por produtos florestais, principalmente por produtos madeireiros, levou a um aumento progressivo da área de florestas plantadas. Recentemente, essa área ultrapassou 6,5 milhões de hectares, sendo o gênero Eucalyptus o de maior expressão por representar aproximadamente $75 \%$ da área de florestas plantadas no país, em 2011 (ABRAF, 2012).

O desafio da silvicultura é a produção sustentável de madeira, uma vez que a rápida taxa de crescimento dessas espécies eleva a demanda sobre os recursos do solo, principalmente por água e nutrientes (Bellote et al., 2008). Segundo Zaia \& Gama-Rodrigues (2004), estudos sobre a ciclagem de nutrientes em povoamentos de eucalipto permitem avaliar possíveis alterações decorrentes de técnicas de manejo aplicadas, possibilitando inferir sobre a sustentabilidade da produção.

$\mathrm{O}$ acúmulo e a distribuição de nutrientes nos diversos compartimentos da planta e no solo podem servir como indicadores de diferenças entre os ecossistemas, em especial no que tange à disponibilidade de nutrientes para as plantas (Cunha et al., 2005). Para Spangenberg et al. (1996), as quantidades de nutrientes encontradas nos diversos compartimentos no sistema solo-planta (parte aérea, raízes, serapilheira e solo) são importantes para a compreensão da estrutura do ecossistema, assim como para definição de estratégias que visem à manutenção da sustentabilidade do ecossistema florestal. Entretanto, a maioria dos estudos refere-se apenas à parte aérea e não leva em consideração o compartimento subterrâneo (Ribeiro et al., 2011).
Experimentos relacionados à biomassa da serapilheira também são importantes na produtividade de um ecossistema, com papel fundamental na ciclagem de nutrientes (Villa Lobos-Vega et al., 2011). Mesmo que os teores de nutrientes na serapilheira proveniente de solos menos férteis sejam menores que em solos mais férteis, a serapilheira constitui uma das principais fontes de nutrientes do sistema (GamaRodrigues \& Barros, 2002). De acordo com Silva \& Mendonça (2007), a matéria orgânica (MO) do solo sob plantações florestais tem grande importância no fornecimento de nutrientes às plantas, na retenção de cátions, na complexação de elementos tóxicos e micronutrientes, na estabilidade da estrutura, na infiltração e retenção de água, na aeração e na atividade microbiana, constituindo-se, assim, num componente fundamental e determinante da capacidade produtiva de solos altamente intemperizados, como a maioria dos solos do bioma Cerrado.

A sustentabilidade da produtividade de uma floresta é determinada, entre outros fatores, pelo balanço de nutrientes no sistema solo-planta (Santana et al., 2008). Nesse sentido, este trabalho teve por objetivo determinar a produção da biomassa e o conteúdo de nutrientes em diferentes compartimentos das árvores de um povoamento de Eucalyptus urophylla x $E$. grandis, na Fazenda Água Limpa, Distrito Federal.

\section{MATERIAL E MÉTODOS}

\section{Descrição da área de estudo}

A área de estudo está localizada na Fazenda Água Limpa (FAL), propriedade da Universidade de Brasília 
(UnB), com 4.340 ha, localizada a $32 \mathrm{~km}$ de Brasília, DF, com parcela estabelecida nas coordenadas $15^{\circ} 56^{\prime} \mathrm{S}$ e $47^{\circ} 55^{\prime} \mathrm{W}$ e $15^{\circ} 59^{\prime} \mathrm{S}$ e $47^{\circ} 58^{\prime} \mathrm{W}$. A altitude média da região é de $1.100 \mathrm{~m}$, com predominância de Latossolo Vermelho distrófico e de vegetação primária Cerrado stricto sensu. De acordo com a classificação de Köppen, o clima é do tipo Aw, com temperaturas mínima e máxima de 12 e $28,5^{\circ} \mathrm{C}$, respectivamente, e precipitação pluvial média anual de $1.500 \mathrm{~mm}$, com pronunciada estação seca nos meses de julho a setembro.

O experimento foi conduzido em uma área de 1,2 ha, plantada com um híbrido de Eucalyptus urophylla $\mathrm{x} E$. grandis, no espaçamento $3 \times 2 \mathrm{~m}$, com idade de 60 meses e densidade média do povoamento de 1.300 indivíduos $\mathrm{ha}^{-1}$. O preparo reduzido do solo foi feito com subsolagem a $70 \mathrm{~cm}$ de profundidade, com a incorporação de $500 \mathrm{~kg} \mathrm{ha}^{-1}$ de superfosfato simples e 280 g/planta de NPK na mistura granulada 20-5-20, mais B e Zn, com a primeira aplicação com 15 dias após o plantio; e a segunda, no início do período chuvoso. A área de estudo passou por um incêndio em setembro de 2011, após quatro anos da implantação do plantio, porém sem interferir na sobrevivência do povoamento.

\section{Cubagem das árvores}

Foi delimitada ao acaso uma parcela de $20 \times 30 \mathrm{~m}$ no interior do povoamento florestal, em que foi mensurada a circunferência à altura do peito (CAP) de todas as árvores incluídas na parcela (78 árvores), a fim de obter o CAP médio. Em seguida, três árvores representativas do povoamento com CAP igual a 38,2, 38,4 e $38,5 \mathrm{~cm}$, com copa bem formada e sem falhas na linha de plantio e entrelinhas adjacentes, foram abatidas para cubagem. Primeiramente, as árvores abatidas tiveram a altura total e comercial (até a circunferência de $5 \mathrm{~cm}$ ) mensuradas, e o fuste foi cubado pelo método de Smalian para obtenção do seu volume. Posteriormente, foram separados e pesados isoladamente os compartimentos das três árvores amostradas: folhas, galhos, casca e lenho. A fim de obter uma amostra representativa para a análise química dos compartimentos das árvores, as amostras do lenho foram seccionadas em toretes com motosserra; coletaram-se frações da serragem ao longo do fuste, da casca ao longo do fuste (a cada 0,5 m), dos galhos, que foram seccionados em pequenos pedaços, e das folhas.

Todas as amostras coletadas em campo foram secas em estufa de ventilação forçada de ar $\left(65 \pm 5{ }^{\circ} \mathrm{C}\right)$ até obtenção da biomassa seca constante e pesada em balança de precisão, com a finalidade de obter o fator de correção dos compartimentos da árvore e a estimação da biomassa seca por hectare. Após essa etapa, todas as amostras foram encaminhadas ao laboratório de análise química de solo e planta, para determinar o teor de macronutrientes, de acordo com Embrapa (2011). Diante dos valores corrigidos da biomassa seca e dos teores de macronutrientes encontrados em cada compartimento, foram extrapoladas as quantidades médias de nutrientes por hectare.

\section{Amostragem de raízes}

Para coleta de raízes, foram escavados 10 monólitos de formato circular, com diâmetro médio de $23 \mathrm{~cm}$, na área útil de cada árvore abatida, sendo esses estratificados em três intervalos de profundidade (0-20, 20-40 e 40-60 cm). Os monólitos foram distribuídos em forma de cruz a partir da cepa de cada árvore abatida, a uma distância de $50 \mathrm{~cm}$ da cepa e, os demais, a $50 \mathrm{~cm}$ um do outro, sendo demarcados dois monólitos para cada lado na direção da linha de plantio e três para cada lado na direção perpendicular à linha de plantio (entrelinhas).

As raízes de eucalipto foram separadas do solo e dos demais materiais vegetais com auxílio de peneiras com malha de $1 \mathrm{~mm}$. Em seguida, foram lavadas para retirar o solo aderido a elas, colocando-as sobre papeltoalha para escorrer o excesso de água; pesadas em balança de precisão com a finalidade de obter a massa úmida; e postas para secar em estufa de ventilação forçada de $\operatorname{ar}\left(65 \pm 5^{\circ} \mathrm{C}\right)$ até obtenção do peso constante de biomassa seca. Posteriormente, as raízes separadas por árvore, monólito e intervalo de profundidade foram homogeneizadas e as amostras resultantes encaminhadas ao laboratório para definir o teor de macronutrientes. Diante dos valores de biomassa seca e teores de macronutrientes encontrados para cada amostra, foram extrapolados valores médios de biomassa e macronutrientes por hectare.

\section{Amostragem de serapilheira}

Para coleta da serapilheira, foram lançados aleatoriamente gabaritos metálicos de $0,25 \mathrm{~m}^{2} \mathrm{em}$ cinco pontos amostrais distribuídos pela área, onde se coletou o material depositado sobre a superfície do solo, originado tanto do eucalipto quanto da vegetação herbácea do sub-bosque. O material coletado em cada ponto foi pesado separadamente e, após ser homogeneizado, extraiu-se uma amostra composta, que foi pesada e levada para estufa de ventilação forçada de $\operatorname{ar}\left(65 \pm 5^{\circ} \mathrm{C}\right)$ até obtenção de biomassa seca constante. Após pesagem em balança de precisão, essa amostra foi encaminhada ao laboratório para discriminar os teores de macronutrientes. A partir dos valores de biomassa seca e teor de macronutrientes, foram feitas extrapolações para o valor médio encontrado por hectare.

\section{Amostragem do solo}

Com auxílio de um trado holandês, foram coletadas amostras de solo nas profundidades de 0-20, 20-40 e 40-60 cm, em 20 pontos aleatórios na área. Em seguida, o solo coletado em cada profundidade foi homogeneizado; formaram-se amostras compostas para cada profundidade, que foram encaminhadas para 
caracterização química, de acordo com Embrapa (2011).

Nas análises, determinaram-se: $\mathrm{pH}\left(\mathrm{CaCl}_{2}\right)$, $\mathrm{MO}$, $\mathrm{Al}^{3+}, \mathrm{P}, \mathrm{K}, \mathrm{S}, \mathrm{Ca}^{2+}, \mathrm{Mg}^{2+}$, capacidade de troca catiônica total (T) e efetiva (t), saturação por bases, saturação por $\mathrm{Al}(\mathrm{m})$ e soma de bases (SB).

\section{Análise estatística}

Os dados obtidos para os estoques em biomassa e os respectivos teores de nutrientes para os compartimentos arbóreos da parte aérea (folhas, galhos, cascas, lenho e serapilheira) foram submetidos à análise estatística descritiva. Procedeuse à análise de Correlação de Pearson por meio de regressão múltipla para os diferentes compartimentos da árvore. Cada compartimento arbóreo foi considerado uma variável, bem como a serapilheira. Todas essas variáveis foram correlacionadas entre si, obtendo um total de 15 correlações. Realizaramse as análises estatísticas utilizando o Programa Genes (Cruz, 2006).

\section{RESULTADOS E DISCUSSÃO}

\section{Descrição do solo}

No quadro 1, estão apresentados os resultados da caracterização química do solo da área do experimento. Observou-se que os valores de $\mathrm{pH}\left(\mathrm{CaCl}_{2}\right)$ foram menores que 4,3, classificando esse solo como de acidez muito elevada (Tomé Júnior, 1997).

O solo caracterizado como distrófico apresentou saturação por bases $(\mathrm{V})$ menor que $50 \%$, nas três profundidades avaliadas. A saturação por alumínio (m) foi mais elevada na camada superficial, indicando ser um solo muito pobre em cátions, corroborado pelos valores também baixos da capacidade de troca catiônica total (T) e efetiva (t) e da soma de bases (SB) (Sousa \& Lobato, 2004; Ronquim, 2010). Maior teor de $\mathrm{Al}^{3+}$ foi verificado na camada de $0-20 \mathrm{~cm}$ de profundidade, reflexo do maior teor de MO. O teor de MO do solo diminuiu com o aumento da profundidade; na superfície, o teor adequado, passando por médio na camada intermediária e tornando-se baixo na camada mais profunda (Quadro 1).
A MO tem influência sobre as propriedades físicas, químicas e biológicas do solo e, dessa forma, o menor valor encontrado para o $\mathrm{pH}$ nas primeiras camadas avaliadas pode ser em razão do aumento do teor de ácido carbônico, quando da decomposição/ mineralização do material orgânico, contendo substâncias altamente acidificante do meio (Silva \& Mendonça, 2007). Por outro lado, a MO também contribui com a CTC total, entre 20 e $90 \%$ nas camadas superficiais de solos minerais, aumentando a disponibilidade de alguns nutrientes; mas, por causa da acidez do solo, os valores da CTC efetiva são baixos (Silva \& Mendonça, 2007; Ronquim, 2010).

Aliada à decomposição do material vegetal e à exsudação do sistema radicular, há liberação de compostos orgânicos que complexam metais como o $\mathrm{Al}^{3+} \mathrm{e}$, dessa forma, há redução desses materiais nas camadas mais profundas do solo (Silva \& Mendonça, 2007), como pode ser observado nas camadas de 20-40 e $40-60 \mathrm{~cm}$.

Em relação ao teor de $\mathrm{P}$ disponível no solo, verificouse que os valores obtidos são extremamente baixos para todas as profundidades analisadas (Alvarez V. et al, 1999; Sousa \& Lobato, 2004), variando de 0,5 a 0,7 $\mathrm{mg} \mathrm{dm}{ }^{-3}$ (Quadro 1).

A baixa disponibilidade de $\mathrm{P}$ no solo provavelmente reflete $\mathrm{o}$ alto teor de argila (> $60 \%$ ), geralmente encontrado em solos tropicais sob cerrado, resultado do grau avançado de intemperismo, e da precipitação do elemento, quando em solução, com formas iônicas de $\mathrm{Fe}, \mathrm{Al}$ e $\mathrm{Ca}$ e também por sua adsorção pelos oxihidróxidos de $\mathrm{Fe}$ e $\mathrm{Al}$ do solo (Novais et al., 2007). Com relação ao K disponível, na camada de $0-20 \mathrm{~cm}$, o teor encontrado de $30 \mathrm{mg} \mathrm{dm}^{-3}$ estava dentro da média para Cerrado e, nas demais camadas, estava abaixo.

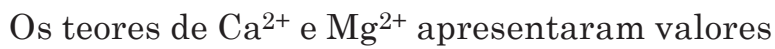
muito baixos e invariáveis $\left(0,1 \mathrm{cmol}_{\mathrm{c}} \mathrm{dm}^{3}\right)$ para as três profundidades avaliadas. Esses elementos se relacionam, e seus teores adequados para solos do Cerrado estão entre 2 e $9 \mathrm{cmol}_{\mathrm{c}} \mathrm{dm}^{3}$. Nesse solo, o teor encontrado foi de $0,2 \mathrm{cmol}_{\mathrm{c}} \mathrm{dm}^{-3}$, indicando possíveis condições de deficiências nutricionais e necessidade de reposição futura para novos ciclos de plantio

Quadro 1. Características químicas e granulométricas do solo sob floresta de Eucalyptus urophylla $x$ E. grandis, aos 60 meses de idade

\begin{tabular}{|c|c|c|c|c|c|c|c|c|c|c|c|c|c|c|c|c|c|}
\hline Prof. & $\begin{array}{c}\mathrm{pH} \\
\left(\mathrm{CaCl}_{2}\right)\end{array}$ & MO & $\mathbf{P}$ & $\mathbf{K}$ & $\mathrm{S}$ & $\mathrm{Ca}^{2+}$ & $\mathrm{Mg}^{2+}$ & $\mathrm{Al}^{3+}$ & $\mathrm{H}+\mathrm{Al}$ & $\mathbf{T}$ & $\mathbf{t}$ & SB & V & $\mathbf{m}$ & Areia & Silte & Argila \\
\hline $\mathrm{cm}$ & & dag $\mathrm{kg}^{-1}$ & 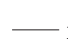 & $\mathrm{g} \mathrm{dm}$ & 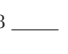 & & & & $\mathrm{cmol}_{\mathrm{c}}$ & $\mathrm{m}^{-3}$ & & & 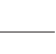 & & $-\%$ & 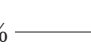 & 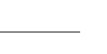 \\
\hline $00-20$ & 3,8 & 4,5 & 0,5 & 30,0 & 1,9 & 0,1 & 0,1 & 0,4 & 8,7 & 9,0 & 0,68 & 0,28 & 3,0 & 57,0 & 5,1 & 29,9 & 65,0 \\
\hline $20-40$ & 3,5 & 3,5 & 0,7 & 17,5 & 1,1 & 0,1 & 0,1 & 0,1 & 5,9 & 6,1 & 0,34 & 0,24 & 3,0 & 33,0 & 4,1 & 32,9 & 63,0 \\
\hline $40-60$ & 4,2 & 2,4 & 0,5 & 12,9 & 1,2 & 0,1 & 0,1 & 0,0 & 5,4 & 5,6 & 0,23 & 0,23 & 4,0 & 0,0 & 4,8 & 34,2 & 61,0 \\
\hline
\end{tabular}




\section{Estoques de biomassa seca e nutrientes nos compartimentos das árvores}

O povoamento estudado apresentou densidade média estimada em 1.300 árvores ha ${ }^{-1}$ com CAP médio de 40,98 cm e altura média de $18,5 \mathrm{~m}$. O volume médio estimado foi de $134,71 \mathrm{~m}^{3} \mathrm{ha}^{-1}$, com incremento médio anual de $26,94 \mathrm{~m}^{3} \mathrm{ha}^{-1} \mathrm{ano}^{-1}$.

No quadro 2, evidenciam-se os teores de macronutrientes encontrados para cada compartimento das árvores e para a serapilheira. Observou-se que os maiores teores de macronutrientes foram encontrados nas folhas, com exceção do $\mathrm{Ca}$, que predomina na serapilheira $\left(10,0 \mathrm{~g} \mathrm{~kg}^{-1}\right)$. No lenho, verificaram-se os menores teores, exceto para $\mathrm{S}$, com menor valor observado nas raízes coletadas na profundidade de $40-60 \mathrm{~cm}\left(0,20 \mathrm{~g} \mathrm{~kg}^{-1}\right)$.

De modo geral, $\mathrm{N}, \mathrm{K}$ e Ca foram os elementos que apresentaram maiores teores nos diferentes compartimentos avaliados; o P destacou-se por apresentar os menores valores entre os demais, na maioria dos compartimentos. Resultados semelhantes ao deste estudo foram obtidos por Zaia \& GamaRodrigues (2004), os quais, ao avaliarem o teor de macronutrientes em três espécies de eucalipto, aos 72 meses de idade, verificaram que nas folhas o teor de $\mathrm{N}$ foi o maior $\left(14,9 \mathrm{~g} \mathrm{~kg}^{-1}\right)$, enquanto na serapilheira, o Ca $\left(11,7 \mathrm{~g} \mathrm{~kg}^{-1}\right)$. Esses autores também encontraram baixo teor de $\mathrm{P}$ tanto nas folhas $\left(0,77 \mathrm{~g} \mathrm{~kg}^{-1}\right)$ quanto na serapilheira $\left(0,33 \mathrm{~g} \mathrm{~kg}^{-1}\right)$. Neste trabalho, os teores de macronutrientes encontraram-se abaixo do limite inferior do intervalo ótimo de macronutrientes para cada compartimento em eucalipto, proposto por Wadt et al. (1998).

No quadro 3, apresentam-se os estoques em biomassa seca e os conteúdos de macronutrientes para cada compartimento avaliado, com seus respectivos percentuais de representatividade. Do total da biomassa seca $\left(90,09 \mathrm{t} \mathrm{ha}^{-1}\right)$ mensurada na área, a maior parte encontra-se na parte aérea das plantas (lenho + casca + galhos + folhas) $(82,68 \%$ ), raízes $(9,35 \%)$ e serapilheira $(7,97 \%)$.

Da biomassa acumulada nas plantas (parte aérea + raízes), verificou-se que o lenho apresentou a maior contribuição, com 69,19\%; posteriormente, raízes $(10,15 \%)$, galhos $(9,75 \%)$, casca $(6,06 \%)$ e folhas $(4,85 \%)$. Gatto et al. (2011), trabalhando em plantações de eucalipto na região Centro-Leste do Estado de Minas Gerais, verificaram que, na idade de 60 meses, a biomassa seca das plantas variou de 87,43 a $177,74 \mathrm{tha}^{-1}$, particionados em lenho $(71 \%)$, raízes (15\%), casca (8\%), galhos (4\%) e folhas (2\%). Já Cunha et al. (2005), ao estudarem apenas a biomassa aérea seca em um plantio de Eucalyptus grandis (96 meses de idade) na região Norte Fluminense (RJ), encontraram biomassa seca de 115,82 $\mathrm{t} \mathrm{ha}^{-1}$, sendo essa distribuída pelos compartimentos lenho (76,9\%), casca $(11,1 \%)$, galhos $(9,6 \%)$ e folhas $(2,6 \%)$. Por sua vez, Santana et al. (2008), ao avaliarem dados de plantios de eucalipto provenientes de diferentes regiões do Brasil, verificaram que em plantios de eucalipto com 78 meses de idade, aproximadamente $93 \%$ da biomassa aérea seca estavam alocadas no tronco (lenho + casca); desses, $13 \%$ corresponderam ao compartimento casca.

Com relação aos conteúdos totais de nutrientes, a ordem da quantidade encontrada foi $\mathrm{N}>\mathrm{K}>\mathrm{Ca}>\mathrm{S}$ $>\mathrm{Mg}>\mathrm{P}$. Resultados semelhantes foram obtidos para a parte aérea, que é responsável por alocar grande parte dos macronutrientes, em razão de apresentar maior quantidade de biomassa seca (Quadro 3). Resultados diferentes foram alcançados por GamaRodrigues \& Barros (2002), os quais, ao avaliarem o conteúdo de nutrientes, exceto $\mathrm{S}$, em plantios de eucalipto com 192 meses de idade, verificaram a seguinte ordem: $\mathrm{Ca}>\mathrm{N}>\mathrm{K}>\mathrm{Mg}>\mathrm{P}$. Tal diferença pode ser justificada por causa da idade do plantio avaliado, uma vez que, de acordo com Barreto et al.

Quadro 2. Teores de macronutrientes nos compartimentos em um plantio de Eucalyptus urophylla $\mathbf{x}$ $E$. grandis, aos 60 meses de idade

\begin{tabular}{|c|c|c|c|c|c|c|}
\hline Compartimento & $\mathbf{N}$ & $\mathbf{P}$ & $\mathbf{K}$ & $\mathbf{C a}$ & Mg & $\mathbf{S}$ \\
\hline Folhas & 13,55 & 1,33 & 8,52 & 7,12 & 2,44 & 1,76 \\
\hline Galhos & 3,70 & 0,53 & 5,59 & 4,96 & 0,83 & 0,42 \\
\hline Casca & 3,32 & 0,33 & 7,12 & 9,91 & 1,32 & 0,33 \\
\hline Lenho & 1,73 & 0,23 & 0,34 & 0,20 & 0,03 & 0,43 \\
\hline Tronco (lenho + casca) & 1,86 & 0,24 & 0,88 & 0,98 & 0,14 & 0,42 \\
\hline Parte Aérea & 2,69 & 0,33 & 1,81 & 1,75 & 0,34 & 0,50 \\
\hline Raízes $0-20 \mathrm{~cm}$ & 4,39 & 0,33 & 2,13 & 2,93 & 0,67 & 0,53 \\
\hline Raízes 20-40 cm & 3,85 & 0,27 & 1,43 & 3,17 & 0,40 & 0,27 \\
\hline Raízes 40-60 cm & 2,65 & 0,27 & 2,30 & 1,93 & 0,53 & 0,20 \\
\hline Raízes $0-60 \mathrm{~cm}$ & 3,79 & 0,29 & 1,91 & 2,79 & 0,54 & 0,36 \\
\hline Parte Aérea + raízes & 2,80 & 0,33 & 1,82 & 1,85 & 0,36 & 0,48 \\
\hline Serapilheira & 7,20 & 0,50 & 0,40 & 10,00 & 2,10 & 1,10 \\
\hline
\end{tabular}


Quadro 3. Biomassa seca (BS) e conteúdo de nutrientes, com seus respectivos percentuais, nos diferentes compartimentos em um plantio de Eucalyptus urophylla $\times$ E. grandis, aos 60 meses de idade

\begin{tabular}{|c|c|c|c|c|c|c|c|}
\hline Compartimento & BS & $\mathbf{N}$ & $\mathbf{P}$ & $\mathbf{K}$ & $\mathbf{C a}$ & Mg & $\mathrm{S}$ \\
\hline & t ha $^{-1}(\%)$ & \multicolumn{6}{|c|}{$-\mathrm{kg} \mathrm{ha}^{-1}(\%)-$} \\
\hline Folhas & $4,02(4,46)$ & $54,47(19,19)$ & $5,33(17,45)$ & $34,23(22,31)$ & $28,63(12,70)$ & $9,82(21,99)$ & $7,09(14,82)$ \\
\hline Galhos & $8,08(8,97)$ & $29,90(10,53)$ & $4,29(14,04)$ & $45,18(29,45)$ & $40,08(17,78)$ & $6,72(15,05)$ & $3,36(7,03)$ \\
\hline Casca & $5,03(5,58)$ & $16,68(5,88)$ & $1,65(5,41)$ & $35,79(23,33)$ & $49,80(22,09)$ & $6,63(14,85)$ & $1,64(3,44)$ \\
\hline Lenho & $57,36(63,67)$ & $99,15(34,93)$ & $13,22(43,27)$ & $19,28(12,57)$ & $11,64(5,16)$ & $1,87(4,19)$ & $24,82(51,90)$ \\
\hline Tronco (lenho + casca) & $62,39(69,25)$ & $115,83(40,81)$ & $14,87(48,68)$ & $55,06(35,89)$ & $61,44(27,25)$ & $8,50(19,04)$ & $26,46(55,33)$ \\
\hline Total da parte aérea & $74,49(82,68)$ & $200,21(70,54)$ & $24,48(80,16)$ & $134,47(87,65)$ & $130,15(57,72)$ & $25,03(56,08)$ & $36,90(77,18)$ \\
\hline Raízes $00-20 \mathrm{~cm}$ & $3,36(3,73)$ & $14,74(5,19)$ & $1,12(3,67)$ & $7,17(4,67)$ & $9,85(4,37)$ & $2,24(5,02)$ & $1,79(3,75)$ \\
\hline Raízes $20-40 \mathrm{~cm}$ & $3,13(3,47)$ & $12,06(4,25)$ & $0,84(2,74)$ & $4,49(2,93)$ & $9,92(4,40)$ & $1,25(2,81)$ & $0,84(1,75)$ \\
\hline Raízes $40-60 \mathrm{~cm}$ & $1,92(2,13)$ & $5,10(1,80)$ & $0,51(1,68)$ & $4,42(2,88)$ & $3,72(1,65)$ & $1,03(2,30)$ & $0,38(0,80)$ \\
\hline Raízes $(0-60 \mathrm{~cm})$ & $8,42(9,35)$ & $31,90(11,24)$ & $2,47(8,87)$ & $16,08(10,48)$ & $23,50(10,42)$ & $4,52(10,12)$ & $3,01(6,30)$ \\
\hline Serapilheira & $7,18(7,97)$ & $51,71(18,22)$ & $3,59(11,76)$ & $2,87(1,87)$ & $71,82(31,85)$ & $15,08(33,79)$ & $7,90(16,52)$ \\
\hline Total & $90,09(100)$ & $283,82(100)$ & $30,54(100)$ & $153,42(100)$ & $225,47(100)$ & $44,63(100)$ & $47,82(100)$ \\
\hline
\end{tabular}

(2012), os teores de $\mathrm{N}$ por unidade de biomassa tendem a diminuir com o aumento da idade do povoamento, já que há acréscimo da ciclagem bioquímica e da eficiência do uso do $\mathrm{N}$ para a produção de madeira.

Os maiores conteúdos de $\mathrm{N}\left(99,15 \mathrm{~kg} \mathrm{ha}^{-1}\right)$, $\mathrm{P}\left(13,22 \mathrm{~kg} \mathrm{ha}^{-1}\right)$ e S $\left(24,40 \mathrm{~kg} \mathrm{ha}^{-1}\right)$ foram observados no compartimento lenho, enquanto K $\left(45,18 \mathrm{~kg} \mathrm{ha}^{-1}\right)$, Mg (9,82 kg ha-1) e Ca (49,80 kg ha $\left.{ }^{-1}\right)$ apresentaram os maiores conteúdos em galhos, folhas e cascas, respectivamente. $\mathrm{O}$ tronco representa os menores percentuais dos elementos $\mathrm{Ca}$ e $\mathrm{Mg}$, com 27,25 e $19,04 \%$, respectivamente. No entanto, a casca é responsável por grande proporção do $\mathrm{Ca}(81,05 \%) \mathrm{e}$ $\mathrm{Mg}(78,0 \%)$ contidos no tronco. A casca representa $22,09 \%$ do total de $\mathrm{Ca}$, sendo inferior apenas à serapilheira, com $31,85 \%$. Resultados semelhantes foram obtidos por Zaia \& Gama-Rodrigues (2004), os quais encontraram 67,73 e $64,74 \%$ do Ca do tronco contido nas cascas para E. grandis e E. camaldulensis, respectivamente; para E. pellita, esses mesmos autores obtiveram resultados diferentes, apenas 19,06\% do Ca do tronco estavam contido nas cascas.

Com relação ao conteúdo de $\mathrm{N}, 70,54 \%$ encontravam-se na parte aérea; $18,22 \%$, na serapilheira; e 11,24\%, nas raízes. Do total da parte aérea, $57,85 \%$ foram verificados no tronco. Barreto et al. (2012), ao avaliarem o conteúdo de $\mathrm{N}$ na parte aérea e na serapilheira de plantios de eucalipto com diferentes idades, em Aracruz, ES, verificaram que grande parte do conteúdo desse elemento encontravase alocado no tronco e, em sequência, na serapilheira. Para a idade de cinco anos, esses autores verificaram o total de $322,1 \mathrm{~kg} \mathrm{ha}^{-1}$; desse total, 51,5; 31,6; e 16,9\% foram observados no tronco, na serapilheira e nos galhos+folhas, respectivamente.

No compartimento raízes, verificou-se que esse foi responsável por acumular quantidade significativa de biomassa $(10,15 \%)$ e, consequentemente, de macronutrientes. Gatto et al. (2011) verificaram que as raízes apresentaram cerca de $15 \%$ da biomassa das plantas em povoamentos de eucalipto com diferentes idades (24 a 120 meses). A maior quantidade de raízes (39,9\%) foi mensurada na camada de 0-20 $\mathrm{cm}$, com tendência a decrescer em profundidade. Witschoreck et al. (2003), ao quantificarem apenas raízes finas $(<2,0 \mathrm{~mm}) \mathrm{em}$ plantios de $E$. urophylla, aos 120 meses de idade, em Santa Maria, RS, encontraram biomassa seca de 1.451,6 $\mathrm{kg} \mathrm{ha}^{-1}$; desse total, $57,9 \%$ estavam concentradas nos primeiros $20 \mathrm{~cm}$ do solo. Já Navroski et al. (2010), ao avaliarem a biomassa de raízes de E. cloesiana, aos 216 meses de idade, até a profundidade de $20 \mathrm{~cm}$, encontraram biomassa seca de $1.266,44 \mathrm{~kg} \mathrm{ha}^{-1}$, sendo mais da metade concentrada a $0-5 \mathrm{~cm}$ de profundidade. Esses resultados estão de acordo com os deste trabalho, e evidenciam a importância de se quantificarem as raízes em estudos envolvendo o balanço de nutrientes.

Quanto aos macronutrientes acumulados nas raízes, a ordem foi: $\mathrm{N}>\mathrm{Ca}>\mathrm{K}>\mathrm{Mg}>\mathrm{S}>\mathrm{P}$. Observou-se que o $\mathrm{N}$ e o Ca foram os mais abundantes, com 31,90 e 23,50 kg ha-1, respectivamente. Assim como a biomassa radicular, os conteúdos de nutrientes decrescem à medida que aumenta a profundidade. As raízes foram responsáveis pelo acúmulo de, aproximadamente, $11,90 \%$ dos nutrientes contidos na biomassa das árvores e 9,57 \%, da biomassa total. Esses resultados evidenciam que as raízes são capazes de estocar quantidade significativa de nutrientes, tornando importante a consideração desses estoques no balanço de nutrientes no sistema solo-planta. Gatto et al. (2010) comentaram que o plantio de espécies florestais que apresentam maior quantidade de raízes possibilita a alocação de grande quantidade de $\mathrm{C}$ orgânico no solo, que permaneceria estocado por 
período relativamente longo no solo, em comparação com o C orgânico estocado na biomassa.

Para a serapilheira, foi estimada biomassa seca de 7,18 t ha-1 (Quadro 3). Barreto et al. (2012) verificaram aporte de serapilheira de 1,6; 3,8;15,3; e 22,9 t ha $^{-1}$, respectivamente, para as idades de 12,36 , 60 e 156 meses, em plantios comerciais de eucalipto, em Aracruz, ES. Gatto et al. (2011) encontraram uma média de 19,03 t ha-1 em plantios de eucalipto aos 60 meses de idade, provenientes de cinco áreas no CentroLeste de Minas Gerais. Uma das possíveis explicações para a baixa quantidade de serapilheira encontrada neste trabalho foi a ocorrência do fogo, 15 meses antes das avaliações. O compartimento serapilheira apresentou quantidade significativa dos conteúdos de nutrientes, com destaque para o Ca com $71,82 \mathrm{~kg} \mathrm{ha}^{-1}$, sendo a ordem verificada: $\mathrm{Ca}>\mathrm{N}>\mathrm{Mg}>\mathrm{S}>\mathrm{P}>\mathrm{K}$. Esses resultados podem ser explicados pelo maior teor de Ca nesse compartimento (Quadro 2). Em trabalho desenvolvido por Cunha et al. (2005), os conteúdos de Ca e N na serapilheira coletada em plantios de eucalipto (96 meses de idade; 18 e 60 meses após a rebrota) apresentaram pouca variação $(1,0$ a $1,2 \%)$.

No quadro 4, encontra-se a análise de correlação de Pearson feita entre os compartimentos da planta em relação à biomassa. Verifica-se que a maior ordem de correlação existente é entre a folha $\times$ casca $(0,9988)$, sendo de pouca diferença entre a correlação de folha $\times$ tronco $(0,9977)$ e casca $\times$ tronco $(0,9987)$; menor correlação foi encontrada para galho $\times$ lenho $(-0,0581)$.

O cenário do balanço de nutrientes no povoamento após a colheita está apresentado na figura 1. Esse cenário considera a remoção do tronco (casca + lenho) do sistema, resultando em saldo positivo, confirmando a tese de que o balanço final, para a maioria dos nutrientes, é positivo. Isso permite a afirmativa de que os plantios de eucalipto, quando corretamente manejados, não exaurem o solo, podendo sim beneficiálo. Considerando um segundo ciclo da floresta, o $\mathrm{PeS}$ teriam um déficit de 10,66 e $23,16 \mathrm{~kg} \mathrm{ha}^{-1}$, respectivamente, necessitando de adubação. Em contrapartida, os conteúdos de K, Ca e Mg estariam adequadas durante 1,$98 ; 3,62$; e 11,83 ciclos, respectivamente. Todavia, esses nutrientes só estariam disponíveis no solo após a mineralização da serapilheira (ciclagem bioquímica), bem como pela retranslocação interna dos nutrientes (Gonçalves et al., 2004).

Os conteúdos de $\mathrm{Ca}, \mathrm{K}$ e $\mathrm{Mg}$ foram os que apresentaram os maiores estoques de nutrientes no sistema (solo, serapilheira, raízes, galhos, folhas); $\mathrm{P}$ e $\mathrm{S}$ apresentaram os menores estoques disponibilizados no sistema. Resultado semelhante foi encontrado por Viera (2012), ao avaliar plantios de Eucalyptus sp. Câmara et al. (2000) observaram no primeiro ano após o corte balanço positivo para $\mathrm{K}, \mathrm{Ca}, \mathrm{Fe}$ e Na; e negativo, para Mg. Cunha et al. (2005) verificaram que o balanço de nutrientes foi positivo, e maior reserva de nutrientes no solo do que absorvido pelas plantas.

Constatou-se que a colheita apenas do lenho representa expressiva redução dos nutrientes exportados no sistema, proporcionando maior sustentabilidade da produção florestal. Entretanto, no balanço geral, o estoque de nutrientes disponível no solo não é suficiente para um novo ciclo de cultivo da floresta, para a condição estudada.

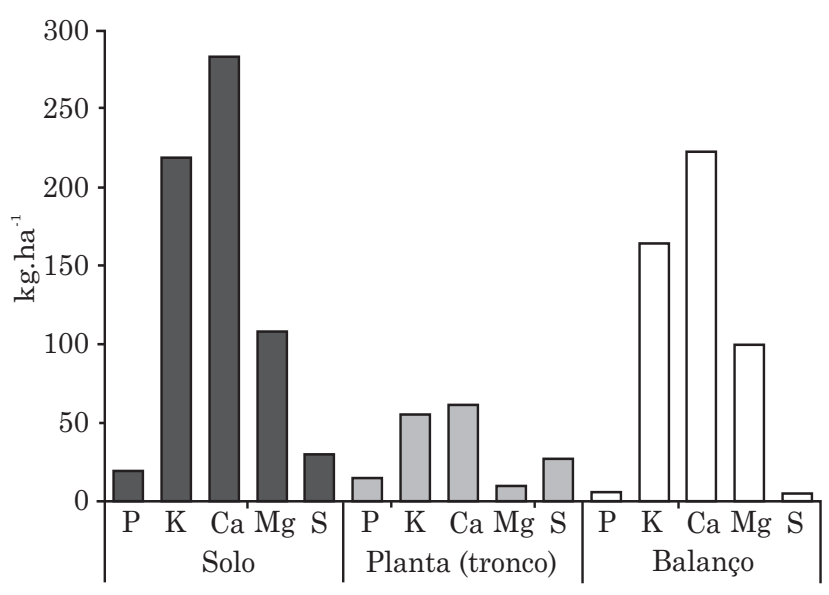

Figura 1. Balanço de nutrientes no sistema soloplanta em plantio de Eucalyptus urophylla $\mathrm{E}$. grandis, aos 60 meses de idade.

Quadro 4. Matriz de Correlação de Pearson entre os compartimentos da planta em relação à biomassa seca em um plantio de Eucalyptus urophylla $\mathrm{x}$ E. grandis, aos 60 meses de idade

\begin{tabular}{lcccccc}
\hline Compartimento & Folha & Galho & Casca & Lenho & Tronco & Serapilheira \\
\hline Folha & 1 & $-0,52$ & $0,9988^{* *}$ & $-0,1623^{\mathrm{ns}}$ & $0,9977^{* *}$ & $-0,189^{\mathrm{ns}}$ \\
Galho & & 1 & $-0,5127^{\mathrm{ns}}$ & $-0,0581^{\mathrm{ns}}$ & $-0,4773^{\mathrm{ns}}$ & $0,6407^{\mathrm{ns}}$ \\
Casca & & 1 & $-0,1176^{\mathrm{ns}}$ & $0,9986^{* *}$ & $-0,1889^{\mathrm{ns}}$ \\
Lenho & & & 1 & $-0,1324^{\mathrm{ns}}$ & $-0,1629^{\mathrm{ns}}$ \\
Tronco & & & & & 1 & $-0,1494^{\mathrm{ns}}$ \\
Serapilheira & & & & & & 1 \\
\hline
\end{tabular}

ns: não significativo, ${ }^{* *}$ significativo a $1 \%$ pelo teste t de Student. 


\section{CONCLUSÕES}

1. O lenho é o compartimento das árvores que apresenta o maior acúmulo de biomassa total $(63,67 \%)$, seguido pelas raízes $(9,35 \%)$, galhos $(8,97 \%)$, casca $(5,58 \%)$ e folhas $(4,46 \%)$, refletindo, consequentemente, no maior acúmulo de macronutrientes.

2. As raízes, segundo compartimento das árvores em termos de biomassa total $\left(8,42 \mathrm{t} \mathrm{ha}^{-1}\right)$ e conteúdo de macronutrientes estocados $(\mathrm{N}>\mathrm{Ca}>\mathrm{K}>\mathrm{Mg}>\mathrm{S}>\mathrm{P}$ ), apresentam decréscimo desses valores com o aumento da profundidade.

3. O balanço de macronutrientes no sistema soloplanta evidenciou-se positivo para todos os elementos analisados; porém, para $\mathrm{P}$ e $\mathrm{S}$ há déficit de 10,66 e $23,16 \mathrm{~kg} \mathrm{ha}^{-1}$, respectivamente, para o próximo ciclo de cultivo da floresta, indicando a necessidade de reposição dos nutrientes exportados pela colheita florestal, tendo em vista manutenção da produtividade e da sustentabilidade do sistema.

\section{LITERATURA CITADA}

ALVAREZ V., V.H.; NOVAIS, R.F.; BARROS, N.F.; CANTARUTTI, R.B. \& LOPES, A.S. Interpretação dos resultados das análises de solos. In: RIBEIRO, A.C.; GUIMARÃES, P.T. \& ALVAREZ V., V.H., eds. Recomendação para o uso de corretivos e fertilizantes em Minas Gerais: $5^{a}$ aproximação. Viçosa, MG, Comissão de Fertilidade do Solo do Estado de Minas Gerais, 1999. p.25-32.

ASSOCIAÇÃO BRASILEIRA DOS PRODUTORES DE FLORESTAS PLANTADAS - ABRAF. Anuário estatístico da ABRAF 2012, ano base 2011. Brasília, 2012. 150p.

BARRETO, P.A.B.; GAMA-RODRIGUES, A.C.; GAMARODRIGUES, E.F. \& BARROS, N.F. Nitrogen balance in soil under eucalyptus plantations. R. Bras. Ci. Solo, 36:1239-1248, 2012.

BELLOTE, A.F.G.; DEDECEK, R.A. \& SILVA, H.D. Nutrientes minerais, biomassa e deposição de serapilheira em plantios de Eucalyptus com diferentes sistemas de manejo de resíduos florestais. Pesq. Flor. Bras., 56:31-41, 2008.

CÂMARA, C.D.; LIMA, W.P. \& VIEIRA, S.A. Corte raso de uma plantação de Eucalyptus saligna de 50 anos: impactos sobre a ciclagem de nutrientes em uma microbacia experimental. Sci. For., 57:99-109, 2000.

CUNHA, G.M.; GAMA-RODRIGUES, A.C. \& COSTA, G.S. Ciclagem de nutrientes em Eucalyptus grandis W. Hill ex Maiden no Norte Fluminense. R. Árvore, 29:353-363, 2005 .

CRUZ, C.D. Programa GENES - Análise multivariada e simulação. Viçosa, MG, Universidade Federal de Viçosa, 2006. v.1, 175p.
EMPRESA BRASILEIRA DE PESQUISA AGROPECUÁRIA EMBRAPA. Centro Nacional de Pesquisa de Solos. Manual de métodos de análise de solo. 2.ed. Rio de Janeiro, 2011. 212p.

GAMA-RODRIGUES, A.C. \& BARROS, N.F. Ciclagem de nutrientes em floresta natural e em plantios de eucalipto e de dandá no sudeste da Bahia, Brasil. R. Árvore, 26:193207, 2002.

GATTO, A.; BARROS, N.F.; NOVAIS, R.F.; SILVA, I.R.; LEITE, H.G.; LEITE, F.P. \& VILLANI, E.M.A. Estoques de carbono no solo e na biomassa em plantações de eucalipto. R. Bras. Ci. Solo, 34:1069-1079, 2010.

GATTO, A.; BARROS, N.F.; NOVAIS, R.F.; SILVA, I.R.; LEITE, H.G. \& VILLANI, E.M.A. Estoque de carbono na biomassa de plantações de eucalipto na região centro-leste do Estado de Minas Gerais. R. Árvore, 35:895-905, 2011.

GONÇALVES, J.L.M.; STAPE, J.L.; BENEDETTI, V.; FESSEL, V.A.G. \& GAVA, J.L. An evaluation of minimum and intensive soil preparation regarding fertility and tree nutrition. In: GONÇALVES, J.L.M. \& BENEDETII, V., eds. Forest nutrition and fertilization. Piracicaba, IPEF, 2004. p.13-64.

NAVROSKI, M.C.; BIALI, L.J.; BIANCHIN, J.E.; CAMARGO, L. \& SCHUMACHER, M.V. Quantificação de biomassa e comprimento de raízes finas em povoamento de Eucalyptus cloeziana F. Muell. Recife, PE. R. Bras. Ci. Agron., 5:535-540, 2010.

NOVAIS, R.F.; SMYTH, T.J. \& NUNES, F.N. Fósforo. In: NOVAIS, R.F.; ALVAREZ V., V.H.; BARROS, N.F.; FONTES, R.L.F.; CANTARUTTI, R.L. \& NEVES, J.C.L., eds. Fertilidade do solo. Viçosa, MG, Sociedade Brasileira de Ciência do Solo, 2007. p.471-550.

RIBEIRO, S.C.; FEHRMANN, L.; SOARES, C.P.B.; JACOVINE, L.A.G.; KLEINN, C. \& GASPAR, R.O. Above-and belowground biomass in a Brazilian Cerrado. For. Ecol. Manage., 262:491-499, 2011.

RONQUIM, C.C. Conceitos de fertilidade do solo e manejo adequado para as regiões tropicais. Campinas, Embrapa Monitoramento por Satélite, 2010. 26p. (Boletim de Pesquisa e Desenvolvimento, 8)

SANTANA, R.C.; BARROS, N.F.; NOVAIS, R.F.; LEITE, H.G. \& COMERFORD, N.B. Alocação de nutrientes em plantios de eucalipto no Brasil. R. Bras. Ci. Solo, 32:2723-2733, 2008.

SILVA, I.R. \& MENDOÇA, E.S. Matéria orgânica do solo. In: NOVAIS, R.F.; ALVAREZ V., V.H.; BARROS, N.F.; FONTES, R.L.F.; CANTARUTTI, R.B. \& NEVES, J.C.L., eds. Fertilidade do solo. Viçosa, MG, Sociedade Brasileira de Ciência do Solo, 2007. p.275-374.

SOUSA, D.M.G. \& LOBATO, E. Cerrado: Correção do solo e adubação. 2,ed. Brasília, Embrapa Informação Tecnológica, 2004. 416p.

SPANGENBERG, A.; GRIMM, U.; SILVA, J.R.S. \& FOLSTER, H. Nutrient store and export rates of Eucalyptus globulus plantations in eastern Amazonia (Jari). For. Ecol. Manage., 80:225-234, 1996. 
TOMÉ JÚNIOR, J.B. Manual para interpretação de análise de solo. Guaíba, Agropecuária, 1997. 274p.

VIERA, M. Dinâmica nutricional em um povoamento híbrido de Eucalyptus urophylla $x$ Eucalyptus globulus em Eldorado do Sul-RS, Brasil. Santa Maria, Universidade Federal de Santa Maria, 2012. 119p. (Tese de Doutorado)

VILLA LOBOS-VEGA, R.; GOLDSTEIN, G.; HARIDASAN, M.; FRANCO, A.C.; MIRALLES-WILHELM, F.; SCHOLZ, F.G. \& BUCCI, S.J. Leaf litter manipulations alter soil physicochemical properties and tree growth in a Neotropical savanna. Plant Soil, 346:385-397, 2011.
WADT, P.G.S.; NOVAIS, R.F.; ALVAREZ V., V.H.; FONSECA, S. \& BARROS, N.F. Valores de referência para macronutrientes em eucalipto obtidos pelos métodos DRIS e chance matemática. R. Bras. Ci. Solo, 22:685692, 1998.

WITSCHORECK, R.; SCHUMACHER, M.V. \& CALDEIRA, M.V.W. Estimativa da biomassa e do comprimento de raízes finas em Eucalyptus urophylla S.T. Blake no município de Santa Maria-RS. R. Árvore, 27:177-183, 2003.

ZAIA, F.C. \& GAMA-RODRIGUES, A.C. Ciclagem e balanço de nutrientes em povoamentos de eucalipto na região norte fluminense. R. Bras. Ci. Solo, 28:843-852, 2004. 